\title{
The Mode of Action of Phenanthridines: The Effect of Ethidium Bromide on Cell Division and Nucleic Acid Synthesis
}

\author{
By B. A. NEWTON \\ Medical Research Council Unit for Chemical Microbiology, \\ Biochemical Laboratory, University of Cambridge
}

SUMMARY: The action of 2:7-diamino-9-phenyl-10-ethyl phenanthridinium bromide (ethidium bromide) on the parasitic flagellate Strigomonas oncopelti has been studied. The drug is irreversibly active only against growing organisms. Addition of the drug to cultures of organisms in the logarithmic phase of growth did not result in an immediate inhibition of growth but in a progressive decrease in growth rate; at least a doubling in number of organisms always occurred before multiplication finally ceased. During the period of growth in the presence of drug the deoxyribonucleic acid content of the organisms fell to half its normal value whilst the ribonucleic acid remained approximately constant. Conditions have been determined which permit the synthesis of nucleic acids and proteins by washed suspensions of $S$. oncopelti and the effect of ethidium bromide on these processes has been studied. The drug rapidly inhibits DNA synthesis whereas RNA and protein synthesis continue for a period of 2-3 hr. after the addition of drug. A study has been made of the uptake of ${ }^{14} \mathrm{C}$-labelled ethidium bromide by organisms under conditions which will or which will not permit nucleic acid synthesis. The uptake of drug is of two types: (i) an initial rapid uptake which occurs in the absence of nucleic acid synthesis and which does not affect the subsequent growth of organisms; (ii) an additional uptake by growing organisms which appears to follow the course of RNA synthesis and which results, eventually, in an inhibition of growth.

Certain phenanthridinium compounds, originally synthesized by Morgan, Walls, Browning, Gulbranson \& Robb (1938), possess trypanocidal properties (Browning, Morgan, Robb \& Walls, 1938) and have been used with success against Trypanosoma congolense and T. vivax infections in cattle. Walls (1945) demonstrated that high trypanocidal activity in the phenanthridine series is a property of quaternary salts containing a primary amino group in the 7- and a phenyl group in the 9-position; the activity is much increased by the presence of a second amino group, thus 2:7-diamino-9-phenyl-10-methyl phenanthridinium bromide (dimidium bromide) and the 10-ethyl analogue (ethidium bromide) are particularly effective (Watkins \& Woolfe, 1952; Woolfe 1952).

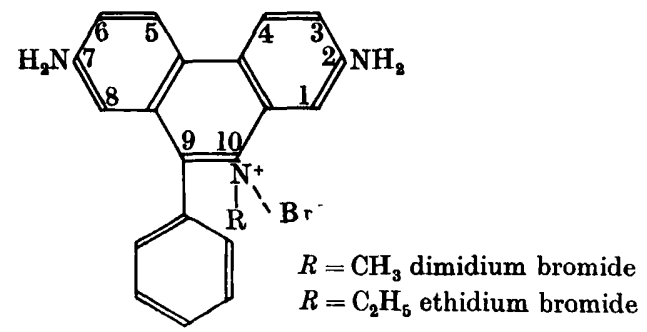


Up to the present time there have been few studies of the mode of action of these compounds. Lock (1950) examined the action of dimidium bromide upon Trypanosoma congolense and T. bruceii maintained in vitro and found that prolonged exposure under these conditions did not kill the trypanosomes, although some loss of infectivity was detected when drug-treated organisms were injected into animals. Chemical methods of analysis failed to show any uptake of drug by trypanosomes. Ormerod $(1951 a, b)$ showed, by histochemical techniques, that after $24 \mathrm{hr}$. contact with dimidium bromide, chromophilic granules containing ribonucleoprotein appeared in the cytoplasm of trypanosomes. He also observed that growth in the presence of dimidium bromide resulted in an increase in the number of multinuclear forms and a decrease in the number of dividing forms of trypanosomes; the motility of the organisms was unaffected. Ormerod obtained similar results with other trypanocidal drugs, including antrycide and suramin, and he postulated that these drugs prevent growth and cell division, but not nuclear division, by splitting cytoplasmic ribonucleoprotein into its constituent protein and nucleic acid. In support of this hypothesis he found that no antrycide could be detected in the nucleus of drug-treated trypanosomes by fluorescent microscopy whereas the cytoplasmic granules were strongly fluorescent, indicating the presence of drug in these structures. The slow action of these drugs, Ormerod suggested, was due to the slow rate of penetration into cells.

The antiviral and antibacterial activity of phenanthridines have been studied recently by Dickinson, Chantrill, Inkley \& Thompson (1953) and by Seaman \& Woodbine (1953); both groups of workers have observed that the action of these drugs can be annulled by addition of nucleic acid to the drugcontaining medium.

Hawking (1953), reviewing current knowledge of trypanocidal compounds, suggested that further study of the mode of action of phenanthridines and related drugs might yield information about nucleic acid metabolism in general and the role of cytoplasmic ribonucleoprotein in particular; such studies have been delayed by the difficulties encountered in the cultivation and maintenance of pathogenic trypanosomes which are sensitive to the phenanthridine drugs. The trypanosomid flagellate Strigomonas oncopelti would seem to be ideally suited for the investigation of these problems; it can be readily cultivated in certain peptones (Lwoff, 1937) or in a simple chemically-defined medium (Newton, 1956) and its growth under these conditions is inhibited by low concentrations of ethidium bromide. The present paper describes the growth inhibitory action of ethidium bromide on $S$. oncopelti and its effect on the synthesis of nucleic acid and protein by this organism.

\section{METHODS}

Organism. The strain of Strigomonas oncopelti previously described (Newton, 1957) was used.

Conditions of culture. Stock cultures were maintained in $5 \mathrm{ml}$. volumes of $3 \%(w / v)$ Evans Bacteriological Peptone containing 0.5\% (w/v) sodium 
chloride and $0.5 \%(\mathrm{w} / \mathrm{v})$ glucose, at an initial $\mathrm{pH}$ value of $7 \cdot 4$ (to be referred to as 'peptone glucose medium'). The medium was sterilized by autoclaving at $15 \mathrm{lb}$./sq.in. for $20 \mathrm{~min}$. Cultures were incubated at $25^{\circ}$ and subcultured every other day. Larger batches of organisms were grown in $50 \mathrm{ml}$. or $500 \mathrm{ml}$. of peptone glucose medium contained in either $150 \mathrm{ml}$. or 1-litre flasks; a $10 \%$ $(\mathrm{v} / \mathrm{v})$ inoculum from a $15 \mathrm{hr}$. culture in the same medium was used and cultures were incubated with shaking in a water bath maintained at $25^{\circ}$.

Preparation of washed suspensions. Organisms were harvested by centrifugation, washed three times with a buffered salts solution containing (\%, $w / v): 0.9 \mathrm{NaCl} ; 0.4 \mathrm{KCl} ; 0.025 \mathrm{Na}_{2} \mathrm{HPO}_{4} .2 \mathrm{H}_{2} \mathrm{O} ; 0.008 \mathrm{KH}_{2} \mathrm{PO}_{4}$; trace metals as described previously (Newton, 1957), and finally suspended in this solution to give a density of $c .10^{8}$ organisms $/ \mathrm{ml}$. This suspension was diluted $1 / 10$ during incubation under the various conditions to be described. Washed suspensions to be used for the study of nucleic acid and protein synthesis were prepared in the same way but under aseptic conditions.

Counts of organisms. In all experiments growth was estimated by counts; $1 \mathrm{ml}$. samples of cultures were fixed with $0.05 \mathrm{ml} .40 \%(\mathrm{w} / \mathrm{v})$ formaldehyde in water. Routinely four counts were made on each sample in a Neubauer haemocytometer, a minimum of $\mathbf{3 0 0}$ organisms being counted in each case. Ten counts/sample were made when cultures were being examined for synchronization of division.

Cytochemical techniques. Smears of organisms were prepared on microscope slides, dried in air and fixed by immersion in absolute methanol for $10 \mathrm{~min}$. Preparations were then stained either with May-Grunwald and Giemsa dyes or with methyl green and pyronin $\mathrm{G}$ as described by Jacobson \& Webb (1952). As a control for the staining of deoxyribonucleoprotein by the above methods, preparations were stained by Feulgen's method after $3 \mathrm{~min}$. hydrolysis in $\mathrm{N}-\mathrm{HCl}$ at $60^{\circ}$. In some cases fixed smears were treated with enzymes before staining; enzymes used were: crystalline protease-free ribonuclease, crystalline deoxyribonuclease (Sigma Chemical Co. U.S.A.) and crystalline trypsin (Worthington Biochemical Sales Co. U.S.A.). Enzyme solutions (0.1\%, w/v) were prepared in glass-distilled water, containing in the case of deoxyribonuclease, $0.075 \mathrm{M}-\mathrm{MgSO}_{4}$. Preparations were incubated in enzyme solutions at $37^{\circ}$ for different periods of time; in each experiment a control preparation was incubated in glass-distilled water alone.

Temperature-induced synchronous division in cultures of Strigomonas oncopelti. Partial synchronization of cell division was obtained by subjecting organisms, suspended in peptone glucose medium, to a series of controlled temperature shifts between $25^{\circ}$ (the optimum growth temperature) and $5^{\circ}$. Suspensions containing $5 \times 10^{5}$ organisms $/ \mathrm{ml}$. were maintained at each temperature for $1 \mathrm{hr}$. and the temperature cycling was continued during $18 \mathrm{hr}$. Rapid temperature shifts were obtained by means of an apparatus similar to that described by Scherbaum \& Zeuthen (1955).

Amino acid, purine and pyrimidine solutions. Solutions $(1.2 \% \mathrm{w} / \mathrm{v})$ of glycine and of the $\mathrm{L}$ isomers of the following amino acids were prepared: L-aspartic and L-glutamic acids, L-arginine, DL-methionine, L-lysine, DL- 
threonine, L-proline, DL-tryptophan, L-tyrosine, L-cysteine, DL-serine, DLphenylalanine, L-histidine, L-valine, DL-alanine, L-leucine and DL-isoleucine; each solution was adjusted to $\mathrm{pH} 7 \cdot 0$. Solutions $(0 \cdot 12 \%, \mathrm{w} / \mathrm{v})$ of each of the following purines and pyrimidines were prepared: adenine, guanine, xanthine, thymine, cytosine and uracil. All these solutions were diluted 1/100 in incubation mixtures.

Incubation mixtures. Incubation mixtures in $150 \mathrm{ml}$. conical flasks contained: $0.6 \mathrm{ml} .20 \%(\mathrm{w} / \mathrm{v})$ glucose, $0.1 \mathrm{ml}$. of each of the amino acid solutions, $0.1 \mathrm{ml}$. of each of the six purine and pyrimidine solutions, $7 \cdot 3 \mathrm{ml}$. of the buffered salts solution described, $1.2 \mathrm{ml}$. of a washed suspension of Strigomonas oncopelti prepared as above, $\mathbf{0 . 5} \mathrm{ml}$. ethidium bromide solution; where any component was omitted an equal volume of buffered salts solution was added. Flasks were closed with cotton plugs and incubated with shaking at $25^{\circ}$. Before the addition of washed organisms and ethidium bromide, incubation mixtures were sterilized by autoclaving at $15 \mathrm{lb} . / \mathrm{sq} . \mathrm{in}$. for $10 \mathrm{~min}$., the cotton plugs being covered with grease-proof paper to prevent loss of contents by evaporation; suspensions of organisms and ethidium bromide were then added with the usual precautions to prevent contamination. Ten $\mathrm{ml}$. from the incubation mixtures were transferred to $15 \mathrm{ml}$. centrifuge tubes at the end of an incubation period and rapidly cooled to $0^{\circ}$. The organisms were harvested by centrifugation, washed with cold buffered salts solution and analysed for protein and nucleic acid.

Protein and nucleic acid content of organisms. Suspensions of organisms after washing were precipitated with perchloric acid to a final concentration of $0 \cdot 2 \mathrm{~N}$. After standing for $1 \mathrm{hr}$. at $5^{\circ}$ the precipitates were centrifuged down, washed twice with cold $0 \cdot 2 \mathrm{~N}$-perchloric acid and then extracted three times successively with $0.5 \mathrm{~N}$-perchloric acid at $70^{\circ}$ for $30 \mathrm{~min}$.; $90-95 \%$ of the total nucleic acid was extracted in the first two treatments and no further extraction took place after the third treatment. Samples of the combined extracts were taken for the determination of total nucleic acid content by measurement of absorption at $260 \mathrm{~m} \mu$. in a Beckman spectrophotometer (Model DU); samples were also taken for the determination of deoxyribose by the diphenylamine method of Burton (1956). The residue remaining after extraction with perchloric acid represented the main protein fraction of the organisms and was either suspended in $0.75 \mathrm{ml} .20 \%(\mathrm{v} / \mathrm{v})$ acetone in water for radioactivity determinations, or was digested by the Kjeldahl method under the conditions described by Chibnall, Rees \& Williams (1943); the ammonia collected after distillation in a Markham apparatus (Markham, 1942) was determined colorimetrically with Nessler's reagent as described by Johnson (1941).

Radioactivity measurements. Samples $(0 \cdot 3 \mathrm{ml}$.) of protein fractions labelled with ${ }^{14} \mathrm{C}$-glycine suspended in $20 \%(\mathrm{v} / \mathrm{v})$ acetone in water were placed on polythene disks of surface area 2 sq.cm.; 1 drop of $1 \%(w / v)$ polyvinyl alcohol was added to each sample and the preparations dried in vacuo. In this way films of less than $1 \mathrm{mg}$./sq.cm. were obtained and self-absorption was less than $5 \%$. The ${ }^{14} \mathrm{C}$ content of dried preparations was estimated by use of an end window Geiger-Muller tube. In experiments designed to measure the uptake 
of ${ }^{14} \mathrm{C}$-labelled ethidium bromide by Strigomonas oncopelti, organisms, after harvesting from a drug-containing medium, were washed three times with cold buffered salts solution and then suspended directly in $0.75 \mathrm{ml} .20 \%(\mathrm{v} / \mathrm{v})$ acetone in water. Samples $(0 \cdot 3 \mathrm{ml}$.) were then plated out as described above, but because the ${ }^{14} \mathrm{C}$-labelled drug had a low specific activity $(0 \cdot 17 \mathrm{mc} . / \mathrm{g}$.) radioactivity measurements were made on a windowless gas-flow (methane) counter operating in the proportional range as described by Taylor \& Sharpe (1951). Backgrounds and samples were counted sufficiently long to give a standard error of less than $5 \%$ in all cases and counts were corrected for self absorption.

Isotopes. Glycine labelled with ${ }^{14} \mathrm{C}$ in the carboxyl position was obtained from the Radiochemical Centre, Amersham; dimidium and ethidium bromides, each labelled with ${ }^{14} \mathrm{C}$ in the 9 position in the phenanthridine ring, were the gift of Boots Pure Drug Co. Ltd., Nottingham.

\section{RESULTS}

\section{Cytochemical observations}

Growth of Strigomonas oncopelti for $12 \mathrm{hr}$. or more in the presence of ethidium bromide $(15 \mu \mathrm{g} . / \mathrm{ml}$.) resulted in the appearance of refractile cytoplasmic granules which were readily seen in living organisms by phase contrast microscopy. In fixed preparations these granules were stained red by pyronin G, blue by May-Grunwald and Giemsa dyes and were Feulgen negative. Treatment of fixed smears of organisms with deoxyribonuclease did not affect the staining properties of the granules; treatment with ribonuclease resulted in a complete loss of basophilic material after $30 \mathrm{~min}$. incubation at $37^{\circ}$ and the residual granules appeared to be weakly eosinophilic. Complete digestion of the granules was achieved by treatment of fixed preparations with ribonuclease and trypsin for $\mathbf{3 0} \mathrm{min}$. at $37^{\circ}$. These findings are in agreement with the results of Ormerod $(\mathbf{1 9 5 1} b)$ who examined the effect of dimidium bromide on Trypanosoma equiperdum and $\boldsymbol{T}$. rhodesiense and they suggest that the granules resulting from drug treatment contain ribonucleoprotein. In contrast to Ormerod's results, no increase in the number of multinuclear forms of Strigomonas oncopelti resulted from growth in the presence of ethidium bromide.

\section{Inhibition of division by ethidium bromide}

Effect of drug concentration. Multiplication of Strigomonas oncopelti in peptone glucose medium was not immediately prevented by the addition of ethidium bromide; 70-80\% increases in number of organisms always occurred after the addition of 20-200 $\mu \mathrm{g}$. ethidium bromide $/ \mathrm{ml}$. to a culture containing c. $5 \times 10^{6}$ organisms $/ \mathrm{ml}$. With less than $20 \mu \mathrm{g}$. ethidium bromide $/ \mathrm{ml}$. greater increases in numbers occurred before multiplication finally stopped (Fig. 1).

Reversibility of ethidium bromide inhibition. When multiplication of Strigomonas oncopelti had ceased in the presence of ethidium bromide, it was not restarted by removal of organisms to a drug-free medium. When organisms were transferred from a drug-containing medium to a drug-free medium at 
intervals before multiplication stopped, they continued to multiply, but at a decreased rate (Fig. 2). The growth rate of drug-treated organisms was related to the time they had been in contact with the drug and was found to remain constant for 3-4 generations, after which there was a gradual increase to the control growth-rate over a further two generations.

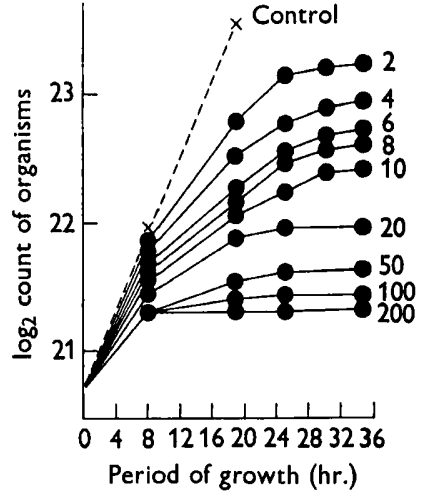

Fig. 1

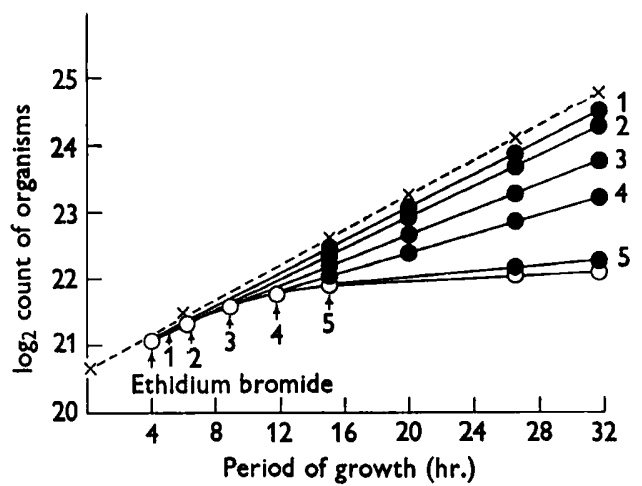

Fig. 2

Fig. 1. Effect of ethidium bromide concentration on the growth of Strigomonas oncopelti. Growth medium; $3 \%$ (w/v) Evans Bacteriological Peptone containing 0.5\% (w/v) $\mathrm{NaCl}+0.5 \%(\mathrm{w} / \mathrm{v})$ glucose. Growth temperature, $25^{\circ}$. Figures on graph indicate concentration of ethidium bromide in $\mu \mathrm{g} . / \mathrm{ml}$. growth medium. Inoculum $=5 \times 10^{6}$ organisms/ml.

Fig. 2. Effect of ethidium bromide on the growth rate of Strigomonas oncopelti. $(\times---\times)$, control culture in peptone glucose medium; $(\mathrm{O}-\mathrm{O}),+15 \mu \mathrm{g}$. ethidium bromide, added after $4 \mathrm{hr}$. of growth at $25^{\circ}$. Samples were removed from control and drug-treated cultures at the times indicated by arrows (1-5): the growth rate of the drug-treated organisms after washing and resuspending in a drug-free growth medium are recorded in curves 1-5. The growth rate of organisms removed from control cultures was not decreased by washing and resuspending in fresh growth medium.

\section{Effect of ethidium bromide on non-dividing organisms}

The effect of ethidium bromide on non-dividing organisms was examined under two conditions: $(a)$ washed organisms suspended in a buffered salts solution containing $0.5 \%(\mathrm{w} / \mathrm{v})$ glucose and incubated at $25^{\circ} ;(b)$ organisms suspended in peptone glucose medium and incubated at $11^{\circ}$. Organisms could be incubated under either of these conditions for 10-12 hr. without any loss in motility or viability, but no division occurred nor was there any increase in the nucleic acid or protein content of organisms. Ethidium bromide $(15 \mu \mathrm{g} . / \mathrm{ml}$.) was added to suspensions of organisms incubated under conditions $(a)$ or $(b)$. Samples were removed at intervals during a $10 \mathrm{hr}$. incubation period and the organisms washed free from drug, resuspended in peptone glucose medium and incubated at $25^{\circ}$; samples from control suspensions containing no drug were treated similarly. In all cases multiplication was estimated by counts of organisms. It was found that ethidium bromide (15 $\mu \mathrm{g} . / \mathrm{ml}$.) was without effect on organisms incubated under either of the above conditions; no decrease in the growth rate of drug-treated organisms, compared with control organisms, occurred after $10 \mathrm{hr}$. contact with the drug. 
Effect of ethidium bromide on synchronously dividing organisms

The slow action of ethidium bromide and the doubling in number of organisms which occurs before the multiplication of Strigomonas oncopelti is stopped by this drug might be due to differences in drug sensitivity of organisms at different stages in the division cycle. Only a small percentage of the total population of a culture of actively growing organisms will be in a particular phase of cell division at any one time; thus if organisms are only sensitive to ethidium bromide at one stage in the division cycle the majority of a population would be expected to divide once after the addition of drug to a culture. By using cultures in which cell division was partially synchronized it has been possible to examine the effect of ethidium bromide on a large number of organisms in approximately the same stage of cell division.

Partial synchronization of cell division in cultures of Strigomonas oncopelti was induced as described above. Fig. $3 a$ shows a typical stepped growth curve obtained by these methods; the initial increase in count of organisms corresponds to the division of $c .70 \%$ of the total population in a period of time equal to about one-quarter of a normal generation time ( $7 \cdot 5-8 \mathrm{hr}$.).

In experiments designed to test the effect of ethidium bromide on organisms in different stages of division, a $400 \mathrm{ml}$. volume of peptone glucose medium containing $c .10^{6}$ organisms $/ \mathrm{ml}$. growing in partial synchrony was divided into $50 \mathrm{ml}$. samples; each sample was placed in a $150 \mathrm{ml}$. conical flask and incubated at $25^{\circ}$. At intervals of $2 \mathrm{hr}$. ethidium bromide (final concentration $20 \mu \mathrm{g} . / \mathrm{ml}$.) was added to the contents of one flask and the incubation continued for a further $2 \mathrm{hr}$. The organisms were then harvested, washed and resuspended in drug-free peptone glucose medium and re-incubated at $25^{\circ}$. Multiplication was estimated by counts of organisms. The contents of one flask to which no drug had been added were harvested at the same time as samples of drug-treated organisms and were treated similarly. The curves obtained for the growth of drug-treated organisms (Fig. $3 b$ ) show that $2 \mathrm{hr}$. contact with ethidium bromide resulted in the same decrease in growth rate, regardless of the stage in cell division at the time of contact with the drug. These results show that the slow action of ethidium bromide is not due to variations in the drug sensitivity of organisms at different stages in the division cycle.

Changes in the nucleic acid content of ethidium bromide-treated organisms. Table 1 records the changes in nucleotide, ribonucleic acid and deoxyribonucleic acid content of organisms during asynchronous growth in the presence or absence of ethidium bromide. When the drug (final concentration, $20 \mu \mathrm{g}$. $/ \mathrm{ml}$.) was added to a culture of initial density $2 \times 10^{6} \mathrm{organisms} / \mathrm{ml}$. multiplication continued for $16 \mathrm{hr}$. and the count of organisms approximately doubled before multiplication ceased; during this time the deoxyribonucleic acid content of organisms fell progressively to half its normal value, whereas the nucleotide and ribonucleic acid content changed little.

Effect of ethidium bromide on nucleic acid and protein synthesis by washed suspensions of Strigomonas oncopelti. Gale \& Folkes (1953), when studying 


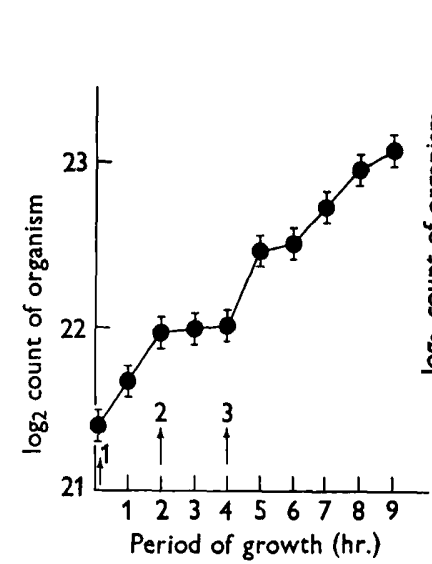

$a$

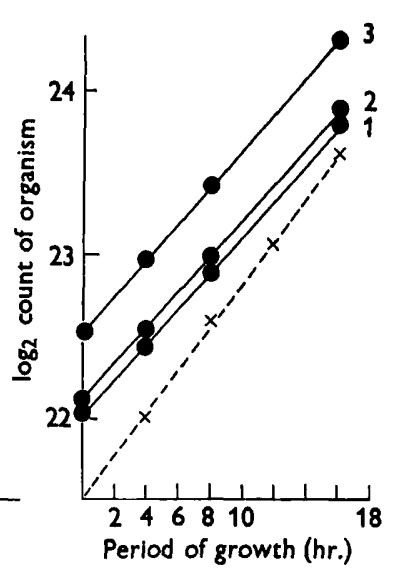

b

Fig. 3a. Partial synchronization of cell division in cultures of Strigomonas oncopelti. A stepped growth curve obtained by subjecting organisms, suspended in peptone glucose medium $\left(5 \times 10^{5}\right.$ organisms $/ \mathrm{ml}$.), to a series of controlled temperature shifts between $25^{\circ}$ and $5^{\circ}$ : suspensions were held at each temperature for $1 \mathrm{hr}$; ; total period of temperature shifts, $18 \mathrm{hr}$.; final growth temperature $25^{\circ}$. Each point on the graph is the mean of 10 counts and the bars through these points represent the standard error of the mean of these determinations.

Fig. 3b. Effect of ethidium bromide on organisms dividing in partial synchrony. Ethidium bromide $(20 \mu \mathrm{g} . / \mathrm{ml}$.) added at $2 \mathrm{hr}$. intervals to $50 \mathrm{ml}$. samples of a culture containing organisms dividing in partial synchrony. Arrows in Fig. $\mathbf{3} a$ indicate the points on the growth curve at which drug was added. After $2 \mathrm{hr}$. contact with the drug organisms were harvested, washed and resuspended in drug-free peptone glucose medium. Growth was estimated by counts of organisms at intervals during $14 \mathrm{hr}$. of incubation at $25^{\circ}$.

Table 1. Changes in the ribonucleic acid, deoxyribonucleic acid and nucleotide content of Strigomonas oncopelti growing in the presence of ethidium bromide

Growth medium; peptone glucose. Growth temp. $25^{\circ}$. Inoculum $=5 \times 10^{6}$ organisms $/ \mathrm{ml}$. Samples were taken at intervals from a control culture (C) and an ethidium bromide $(20 \mu \mathrm{g} . / \mathrm{ml}$.)-containing culture (E); organisms were harvested, washed and their nucleic acid content determined as detailed in the text. The figures indicate changes in nucleotide, ribonucleic acid (both expressed as $\log I_{0} / I$ at $260 \mathrm{~m} \mu . / 10^{\circ}$ organisms) and deoxyribonucleic acid (estimated by the diphenylamine method and expressed as $\log I_{0} / I$ at $600 \mathrm{~m} \mu . / 10^{9}$ organisms) content of organisms growing in the presence or absence of drug during $24 \mathrm{hr}$.

\begin{tabular}{|c|c|c|c|c|}
\hline \multirow{3}{*}{$\begin{array}{c}\text { Time of } \\
\text { sampling } \\
\text { (hr.) }\end{array}$} & \multicolumn{4}{|c|}{$\log I_{o} / I$ at $260 \mathrm{~m} \mu . / 10^{9}$ organisms } \\
\hline & \multicolumn{2}{|c|}{ Nucleotide } & \multicolumn{2}{|c|}{ Ribonucleic acid } \\
\hline & $\mathbf{C}$ & $\mathbf{E}$ & $\mathbf{C}$ & $\mathbf{E}$ \\
\hline 0 & $3 \cdot 6$ & $3 \cdot 5$ & 150 & 160 \\
\hline 2 & $\mathbf{3} \cdot \mathbf{0}$ & $3 \cdot 2$ & 163 & 141 \\
\hline 4 & $\mathbf{3} \cdot \mathbf{0}$ & $3 \cdot 4$ & 149 & 157 \\
\hline 6 & $\mathbf{3} \cdot \mathbf{1}$ & $2 \cdot 9$ & 189 & 152 \\
\hline 8 & $\mathbf{3 \cdot 2}$ & $3 \cdot 1$ & 176 & 142 \\
\hline 12 & $3 \cdot 0$ & $3 \cdot 1$ & 171 & 136 \\
\hline 24 & $\mathbf{2 \cdot 9}$ & $3 \cdot 0$ & 157 & 141 \\
\hline
\end{tabular}

\begin{tabular}{|c|c|}
\hline \multicolumn{2}{|c|}{$\begin{array}{l}\text { Deoxyribonucleic } \\
\text { acid }\end{array}$} \\
\hline C & $\mathbf{E}$ \\
\hline 0.59 & $0 \cdot 65$ \\
\hline 0.55 & 0.58 \\
\hline 0.51 & 0.54 \\
\hline 0.60 & 0.47 \\
\hline 0.60 & $0 \cdot 40$ \\
\hline 0.51 & 0.41 \\
\hline 0.58 & 0.31 \\
\hline
\end{tabular}


nucleic acid and protein synthesis by washed suspensions of Staphylococcus aureus, found that there was an increase in the nucleic acid content of the organisms when they were incubated in the presence of glucose, a mixture of amino acids, purines and pyrimidines; little or no formation of nucleic acid occurred in the absence of amino acids or glucose. Similar results have been obtained for Strigomonas oncopelti; when washed organisms were incubated at $25^{\circ}$ for $5 \mathrm{hr}$. with glucose, purines, pyrimidines and 18 amino acids the ribonucleic acid and protein content of the suspension increased by $70-80 \%$ and the deoxyribonucleic content by 35-45\% (Fig. 4). The addition of ethidium bromide $(20 \mu \mathrm{g} . / \mathrm{ml}$.) to a washed suspension incubated under these conditions resulted in a rapid inhibition of deoxyribonucleic acid synthesis whilst protein and ribonucleic acid synthesis continued for 2-3 hr. (Fig. 5).

\section{Uptake of ${ }^{14} \mathrm{C}$-labelled ethidium bromide by Strigomonas oncopelti}

Uptake by organisms growing in peptone glucose medium. Fig. 6 shows that the uptake of ${ }^{14} \mathrm{C}$-labelled ethidium bromide by organisms growing in a peptone glucose medium continued throughout the period of growth in the presence of the drug. A considerable uptake (c. $3 \mu \mathrm{g}$. ethidium $/ 10^{8}$ organisms) occurred during the lag phase of growth, during which time there was no increase in number of organisms.

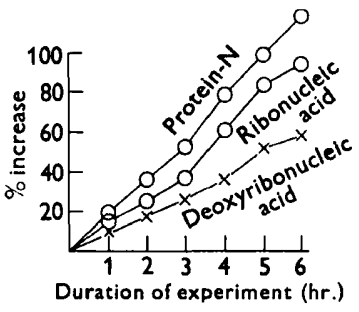

Fig. 4

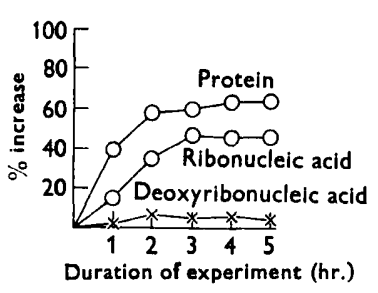

Fig. 5

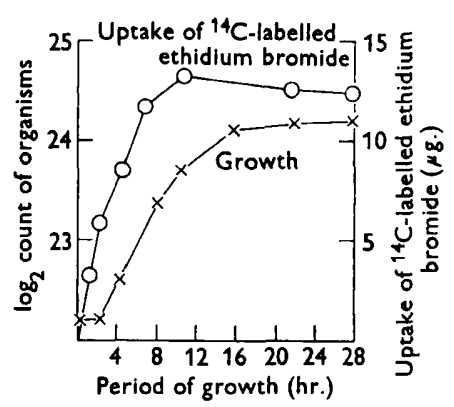

Fig. 6

Fig. 4. Synthesis of ribonucleic acid, deoxyribonucleic acid, and protein by washed Strigomonas oncopelti. Washed organisms suspended in buffered salts solution (pH $7 \cdot 2)$ containing glucose, 18 amino acids, purines and pyrimidines; incubation temp. $25^{\circ}$.

Fig. 5. Effect of ethidium bromide (15 $\mu \mathrm{g} . / \mathrm{ml}$.) on ribonucleic acid, deoxyribonucleic acid and protein synthesis by Strigomonas oncopelti. Washed organisms suspended in buffered salts solution ( $\mathrm{pH} \mathrm{7 \cdot 2)}$ containing glucose, 18 amino acids, purines and pyrimidines; incubation temp. $25^{\circ}$.

Fig. 6. Uptake of ${ }^{14} \mathrm{C}$-labelled ethidium bromide by Strigomonas oncopelti. Growth in peptone glucose medium. Growth temp. $25^{\circ}$.

Release of drug from organisms. To determine whether ethidium bromide which had been bound by organisms was released again during multiplication in a drug-free medium, organisms were suspended in peptone glucose medium containing $10 \mu \mathrm{g} .{ }^{14} \mathrm{C}$-labelled ethidium bromide $/ \mathrm{ml}$. and incubated at $25^{\circ}$ for $4 \mathrm{hr}$. Organisms were then harvested, washed and resuspended in drug-free peptone glucose medium and incubated at $25^{\circ}$ for a further $22 \mathrm{hr}$. Samples 
were taken at intervals during this second incubation for counting the number of organisms and for the determination of ${ }^{14} \mathrm{C}$-labelled drug bound to the organisms. Table 2 shows that there was no significant release of ${ }^{14} \mathrm{C}$-labelled drug from the organisms during $22 \mathrm{hr}$. of growth in a drug-free medium.

Table 2. Uptake of ${ }^{14} \mathrm{C}$-labelled ethidium bromide by Strigomonas oncopelti. Effect of growth in a drug-free medium after an initial period of growth in the presence of drug

Organisms were grown for $4 \mathrm{hr}$. in peptone glucose medium containing $10 \mu \mathrm{g} .{ }^{14} \mathrm{C}$-labelled ethidium bromide/ml., washed three times with drug-free peptone glucose medium and resuspended in this medium. Organisms from samples taken at intervals during a $22 \mathrm{hr}$. period of incubation at $25^{\circ}$ were harvested, washed, suspended in $20 \%(v / v)$ acetone in water and dried on polythene planchettes for radioactivity determinations in a windowless gas-flow (methane) counter.

\begin{tabular}{|c|c|c|}
\hline $\begin{array}{l}\text { Time after } \\
\text { removal from } \\
{ }^{14} \text { C-ethidium } \\
\text { bromide } \\
\text { (hr.) }\end{array}$ & $\begin{array}{c}\text { Organisms } \\
10^{-4} / \mathrm{ml} .\end{array}$ & $\begin{array}{c}\text { Radio- } \\
\text { activity/sample } \\
\text { (counts/min.) }\end{array}$ \\
\hline 0 & $\mathbf{4 4 7}$ & 48 \\
\hline $\mathbf{5}$ & 605 & 48 \\
\hline 10 & 1468 & 45 \\
\hline 22 & 3048 & 43 \\
\hline
\end{tabular}

Uptake of ${ }^{14} \mathrm{C}$-labelled ethidium bromide by washed suspensions. This was studied under two conditions : (i) washed organisms suspended in buffered salts solution containing glucose, purines and pyrimidines; (ii) as condition (i) but with the addition of a mixture of 18 amino acids. Under condition (i) organisms synthesized little or no nucleic acid during $6 \mathrm{hr}$. of incubation at $\mathbf{2 5}^{\circ}$; under condition (ii) a linear increase in the nucleic acid content of organisms occurred. Addition of a mixture of 18 amino acids to organisms incubated under condition (i) initiated nucleic acid synthesis (Fig. 7a). ${ }^{14} \mathrm{C}$-labelled ethidium bromide (final concentration, $10 \mu \mathrm{g} . / \mathrm{ml}$.) was added to organisms incubated under condition (i) and samples for radioactivity determinations were taken at intervals during a $6 \mathrm{hr}$. incubation period at $25^{\circ}$. It was found that drug was rapidly bound by organisms during the first $30 \mathrm{~min}$. of the incubation period (c. $3 \mu \mathrm{g} . / 10^{8}$ organisms) but no more drug was bound during the next $5.5 \mathrm{hr}$.; addition of a mixture of 18 amino acids to the suspension resulted in a $40 \%$ increase in the amount of ${ }^{14} \mathrm{C}$-labelled ethidium bromide bound by the organism. Fig. $7 b$ records these results; the ${ }^{14} \mathrm{C}$ labelled drug bound by organisms is expressed as a percentage of the amount bound during $30 \mathrm{~min}$. incubation under condition (i). The uptake of radioactive drug by organisms incubated under condition (ii) is also shown in Fig. $7 b$.

The effect of dimidium bromide on division and nucleic acid synthesis in Strigomonas oncopelti. Similar experiments to those already described were performed with dimidium bromide; the results showed that this drug has an effect similar to ethidium bromide on the division of Strigomonas oncopelti and on the synthesis of nucleic acid and protein by this organism. 

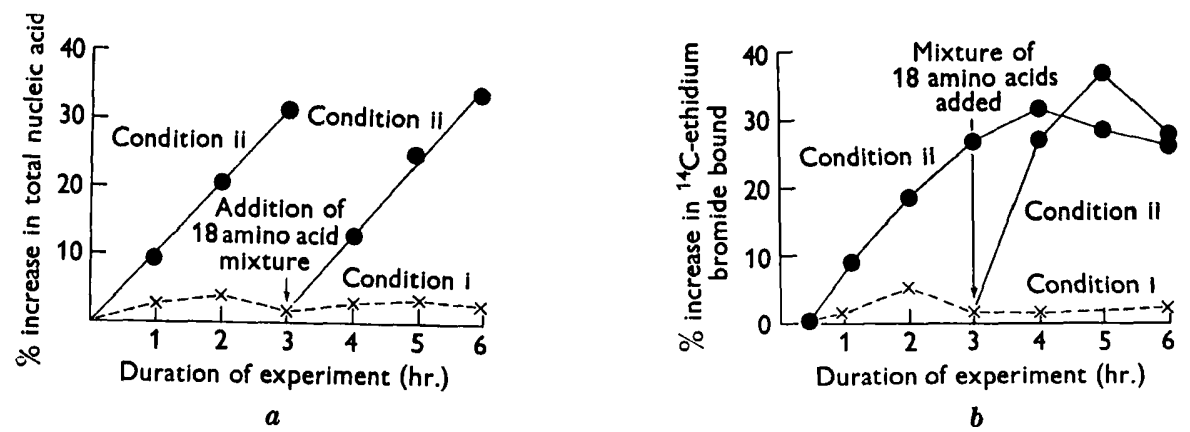

Fig. 7a. Synthesis of nucleic acid by washed suspensions of Strigomonas oncopelti. Condition $i$, organisms suspended in buffered salts solution containing glucose, purines and pyrimidines. Condition $\mathrm{ii}$, as condition $\mathrm{i}$ but with the addition of a mixture of 18 amino acids. Incubation temp. $\mathbf{2 5}^{\circ}$.

Fig. 7 b. Uptake of ${ }^{14} \mathrm{C}$-labelled ethidium bromide by washed suspensions of Strigomonas oncopelti incubated under condition $\mathrm{i}$ or condition ii. The uptake of radioactive drug expressed as \% of increase in the amount bound by organisms during $80 \mathrm{~min}$. incubation under condition $i$. Incubation temp. $\mathbf{2 5}^{\circ}$.

\section{DISCUSSION}

Cytochemical studies led Ormerod $(1951 b)$ to propose that dimidium bromide inhibited the growth of trypanosomes by splitting cytoplasmic ribonucleoprotein into its constituent ribonucleic acid and protein. This hypothesis does not provide an adequate explanation of the results described in the present paper; it would be expected that a compound which caused the disorganization of nucleoprotein by the cleavage of electrostatic bonds would be active against non-growing organisms, but this was found not to be the case.

It is possible to advance a number of explanations for the slow action of ethidium bromide and for the approximate doubling in number of organisms which occurs before the multiplication of Strigomonas oncopelti is stopped by this drug. First, variations in drug sensitivity of organisms during a cell division cycle could produce such an effect; the results of experiments with cultures of synchronously dividing organisms have eliminated this possibility. Secondly, Ormerod $(1951 b)$ suggested that a slow penetration of dimidium bromide into organisms might explain the slow action of the drug. This explanation seems unlikely for the case of $S$. oncopelti since non-growing but actively metabolizing organisms (i.e. organisms incubated under the conditions described which do not permit multiplication or net synthesis of either protein or nucleic acid) can be exposed to both ethidium and dimidium bromide for long periods without any loss of viability. A third possibility is that the drugs penetrate into organisms rapidly but are not inhibitors of multiplication until they become bound on to, or incorporated into, a cellular component which only becomes available for this combination during growth. Such an explanation is compatible with some of the results obtained in the present work, but it does not explain the rapid binding of ${ }^{14} \mathrm{C}$-labelled drugs by non-growing organisms. The results described in the present paper can be explained by postulating two types of combination between drug and organisms: a rapid 
combination with 'primary binding sites' which does not interfere with growth and cell division and which occurs in both non-growing and growing organisms, and then a slower combination with 'secondary binding sites' which become available to the drug during growth. It is this secondary uptake which results in a progressive decrease in the growth rate of organisms. The nature of these binding sites is not yet known, but there is some evidence to suggest that nucleic acid may be involved: the drugs can combine with, and are inactivated by, nucleic acid (Brownlee et al. 1950; Seaman \& Woodbine, 1953); cytochemical studies (Ormerod, 1951b) suggest that the chromophilic granules which appear in the cytoplasm of drug-treated organisms contain ribonucleic acid, protein and bound drug, and the present work indicates that there is a close relationship between the combination of drug with 'secondary binding sites' and ribonucleic acid synthesis.

Inactivation of ribonucleic acid at the time of its synthesis might explain the observed progressive decrease in the growth rate of drug-treated organisms, since a correlation between the growth rate and ribonucleic acid content of cells has now been established for a number of microorganisms (Casperson \& Brand, 1941 ; Jeener \& Brachet, 1944; Caldwell, Mackor \& Hinshelwood, 1950; Gale \& Folkes, 1953). However this would not explain the rapid inhibition of deoxyribonucleic acid synthesis which occurs before the inhibition of either ribonucleic acid or protein synthesis, unless an active ribonucleic acid or ribonucleoprotein is in some way involved in deoxyribonucleic acid synthesis. Such a conclusion cannot be drawn from the experimental evidence available at the present time and a direct interaction between ethidium bromide and deoxyribonucleic acid cannot be excluded. It is hoped that further study of the mechanism of action of phenanthridine drugs may give some information about the interrelationships existing between deoxyribonucleic acid, ribonucleic acid and protein synthesis.

I wish to thank Dr D. H. Marrian of the Department of Radiotherapeutics, Cambridge, for making radioactivity measurements which involved the use of a windowless, gas-flow, counter.

\section{REFERENCES}

Browning, C. H., Morgan, G. T., Robb, J. M. V. \& Walls, L. P. (1938). The trypanocidal action of certain phenanthridinium compounds. J. Path. Bact. 46, 203.

Brownlee, G., Goss, M. D., Goodwin, L. G., Woodbine, M. \& Walls, L. P. (1950). The chemotherapeutic action of phenanthridine compounds. Brit. J. Pharmacol. $5,261$.

Burton, K. (1956). A study of the conditions and mechanism of the diphenylamine reaction for the colorimetric estimation of deoxyribonucleic acid. Biochem. J. 62, 315.

Caldwell, P. C., Mackor, E. L. \& Hinshelwood, C. (1950). The ribose nucleic acid content and cell growth of Bact. lactis aerogenes. J. chem. Soc. p. 3151.

Casperson, T. \& Brand, K. (1941). Nucleotidumsatz und Wachstum bei Presshefe. Protoplasma, 35, 507.

Chibnali, A. C., Rees, M. W. \& Williams, E. F. (1943). The total nitrogen content of egg albumin and other proteins. Biochem. J. 37, 354. 
Dickinson, L., Chantrild, B. H., Inkley, G. W. \& Thompson, M. J. (1953). The antiviral action of phenanthridinium compounds. Brit. J. Pharmacol. 8, 139.

Gale, E. F. \& Folkes, J. P. (1953). The assimilation of amino acids by bacteria. 14. Nucleic acid and protein synthesis in Staphylococcus aureus. Biochem. J. 53, 483.

Hawking, F. (1953). Recent advances in the chemotherapy of protozoal infections. Symposium. Grozth Inhibition and Chemotherapy, p. 88. 6th Congr. Int. Microbiol., Rome.

JACobson, W. \& WebB, M. (1952). The two types of nucleoprotein during mitosis. Exp. Cell Res. 3, 163.

Jeener, R. \& Brachet, J. (1944). Recherches sur l'acide ribonucleiques des levures. Enzymologia, 11, 222.

Johnson, M. J. (1941). Isolation and properties of a pure yeast polypeptidase. J. biol. Chem. 137, 575.

Lock, J. A. (1950). The chemotherapeutic action of phenanthridine compounds. 4. Activity in vitro. Brit. J. Pharmacol. 5, 398.

Lworf, M. (1937). L'aneurine, facteur de croissance pour le flagelle trypanosomide, Strigomonas oncopelti. C.R. Soc. Biol., Paris, 126, 771.

MARKhaM, R. (1942). A steam distillation apparatus suitable for micro-Kjeldahl analysis. Biochem. J. 36, 790.

Morgan, G., Walls, L. P., Browning, C. H., Gulbranson, R. \& Robb, J. M. V. (1938). Researches in the phenanthridine series. 5. The colour and antiseptic properties of quaternary salts. J. chem. Soc. 389.

Newton, B. A. (1956). A synthetic growth medium for the trypanosomid flagellate Strigomonas (Herpetomonas) oncopelti. Nature, Lond. 177, 279.

Newton, B. A. (1957). Nutritional requirements and biosynthetic capabilities of the parasitic flagellate Strigomonas oncopelti. J. gen. Microbiol. 17, 708.

Ormerod, W. E. (1951 a). The mode of action of antrycide. Brit.J. Pharmacol.6, 325.

Ormerod, W. E. (1951b). A study of basophilic inclusion bodies produced by chemotherapeutic agents in trypanosomes. Brit. J. Pharmacol. 6, 334.

Schenbaum, O. \& Zeuthen, E. (1955). Temperature induced synchronous division in the ciliate protozoan Tetrahymena pyriformis growing in synthetic and proteose peptone media. Exp. Cell Res. (Suppl.), 3, 312.

Seaman, A. \& Woodbine, M. (1953). Some aspects of the antibacterial effects of phenanthridine compounds. Atti VI Congr. int. Microbiol., 1, 636.

Taylor, D. \& Sharpe, J. (1951). Nuclear particle and radiation detectors. Proc. Inst. Elect. Engrs. 98, 174.

Walls, L. P. (1945). Researches in the phenanthridine series. 6. The relationship between structure and trypanocidal properties. J. chem. Soc. 294.

WATKINS, T. I. \& Woolfe, G. (1952). Effect of changing the quaternizing group on the trypanocidal activity of dimidium bromide. Nature, Lond. 169, 506.

Woolfe, G. (1952). The trypanocidal activity of phenanthridine compounds. Ann. trop. Med. Parasit. 46, 285. 